\title{
Generating knowledge in a Learning Study: from the perspective of a teacher researcher
}

Anja Thorsten

The self-archived version of this journal article is available at Linköping University Institutional Repository (DiVA):

http:/ / urn.kb.se/ resolve?urn=urn:nbn:se:liu:diva- 139952

N.B.: When citing this work, cite the original publication.

This is an electronic version of an article published in:

Thorsten, A., (2017), Generating knowledge in a Learning Study: from the perspective of a teacher $\begin{array}{llll}\text { researcher, } & \text { Educational 140-154. }\end{array}$ https:/ / doi.org/ 10.1080/ 09650792.2016.1141108

Original publication available at:

https:/ / doi.org/ 10.1080/09650792.2016.1141108

Copyright: Taylor \& Francis (Routledge): SSH Titles

http:// www.routledge.com/ 


\title{
Anja Thorsten
}

\section{Generating knowledge in a Learning Study - from the perspective of a teacher researcher}

\begin{abstract}
The purpose of this article is to discuss and describe how a clinical research method can be used to generate knowledge about teaching and learning. This will be addressed from a teacher researcher's perspective, taking a conducted Learning Study as the departure. Learning Study is an interventionist, iterative and collaborative research approach, focusing on the teaching of an object of learning. The actual study was conducted by a teacher researcher leading a teacher research team in a study about story-writing in primary school. The research process and the results are discussed using four areas that are described as dichotomies by Labaree (2003). Labaree states that teacher researchers need to go from being normative, experimental, personal and particular into being analytical, theoretical, intellectual and universal. By using examples from the Learning Study, I argue that these areas do not have to be seen as dichotomies; instead they can be combined and intertwined. Thus, in a Learning Study, elements from both the teaching practice and the academic practice matter, thus enhancing the possibility that results are useful for practitioners.
\end{abstract}

\section{Introduction}

It has been questioned whether educational research conducted by universities has an impact on teachers in their daily work in the classroom (Elliott, 1991; Hiebert, Gallimore \& Steigler, 2002; Lewis, 2009; Somekh \& Zeichner, 2009). Elliott (1991) states that teachers often cannot relate to academic research, mainly since the research does not address questions that are relevant for them. Therefore, there is a need for research that, to a larger extent, is based on questions raised in the teaching practice (Carlgren, 2012; Cochran-Smith \& Lytle, 1999; Elliott, 2012; Hiebert et al., 2002; Newton \& Burgess, 2008; Somekh \& Zeichner, 2009). Also, there is a need for teachers to lead and to be involved in educational research, since it will influence the process and the results that are gained (Bulterman-Bos, 2008). In this article I argue that the research process as well as the results of a study can benefit from being conducted by teacher researchers. The discussion will be exemplified by experiences from a Learning Study where I was a teacher researcher, leading a team consisting of four co-researchers, all teachers. In a Learning Study, a teacher research team iteratively investigate an object of learning (Lo, 2012; Marton, 2015). In the study at hand, the object of learning was 9-10-yearolds' story-writing.

The specific purpose is to discuss and describe how Learning Study can be seen as a clinical research practice and how the knowledge and perspective of the researcher(s) affect the process as well as the results. 


\section{Teacher researchers}

Instances of teachers as researchers have been more frequently seen during recent years, in Sweden as well as in other countries. According to Cochran-Smith and Lytle (1999), teachers become better practitioners by taking part in research, but also academia can gain from this kind of research, since it can give ideas about new research areas. However, Bulterman-Bos (2008) and Carlgren (2012) state that the involvement of teachers in research not only ensures that relevant questions are addressed and that teachers develop their teaching skills, it also affects the entire research process as well as the results. The knowledge of the researchers is essential for what kind of results are generated.

The knowledge and experience of teachers in the academic world are perceived in different ways. When a teacher enters academia to do research, the focus often is on how to transcend from a teacher to a researcher. Labaree (2003) states that a teacher who becomes a researcher enters a new practice with a different worldview and another focus than they are used to. The transition is related to four areas, where the teacher needs to go from being normative, experimental, personal and particular into being analytical, theoretical, intellectual and universal. According to Labaree, the teacher should not abandon their previous worldview, but instead shift between them. Depending on which practice they are in, emphasis may be on either one of them. Bulterman-Bos (2008) argues that Labaree's statements are based on a view of the researcher as disconnected from the research area. However, views of the researcher as an objective investigator have, during the last decades, been challenged by a number of researchers in Education (see Bulterman-Bos, 2008; CochranSmith \& Lytle, 1999; Elliott, 1991; Newton \& Burgess; Stenhouse, 1981). This means that the researcher can be an active participant in the research and still generate credible and trustworthy results. Based on the work of Polanyi, Bulterman-Bos (2008) discusses Labaree's statements and argues that there is a need for a clinical research practice in education. In this kind of research practice, the research is conducted by researchers that have a large experience of teaching and that are still teaching. According to this view, it is an asset and not a hindrance to be involved in the object of research. The researcher needs to be normative, experimental, personal and particular as well as analytical, theoretical, intellectual and universal (Bulterman-Bos, 2008). These aspects are not contradictory; instead, they can enrich each other.

In this article I will use Labaree's statements and Bulterman-Bos' view of clinical research to discuss and exemplify how this applies to me as a teacher researcher. I will do this based on one of the Learning Studies that I have conducted. The next section will provide information about the method, theory and how the study was carried out.

\section{Doing a Learning Study}

Learning Study can be seen as a form of participatory action research (Pérez, Soto \& Serván, 2010). Earlier, it has mainly been used as professional development for teachers (Carlgren, 2012) and there are several articles written about how the method can have a positive influence on the teaching practice (for example, see Elliott, 2012; Pérez et al., 2010; Tan, 2014). Even if the teachers that took part in this study developed a deeper knowledge about teaching and learning (see Thorsten, 2015), it was not the main aim of the study. Instead, the focus was on generating knowledge about how to teach story-writing. 
The method has similarities with Lesson Study and Design Research (Marton \& Runesson, 2015). It has the same arrangement as a Lesson Study where a group of teachers plan, enact, analyse and revise one or more lessons in two or more cycles. The similarity with Design Research is that it has a theoretical basis and that its contribution is theoretical as well as practical. In a Learning Study, a learning theory is always used in the entire process. The focus is on how an object of learning is constituted and how it can be taught. Another important ingredient is the teachers' practice-based knowledge (Thorsten, 2015). This knowledge is often tacit (see Polanyi, 1962) and is based on experiences teachers have gained when they have handled many different situations in a school context. Other resources in the research process are students' conceptions, the classroom setting and previous research.

Various theories including pedagogical content theories and grand theories of learning such as socio-cultural theories, can be used in a Learning Study. There is also always a theory about teaching and learning. The most common theory to be used is Variation Theory. Variation Theory and Learning Study have been developed together, though they can be used separately. In this actual study they were used together. Since the methodology of a Learning Study is related to Variation Theory, the theory and the method both enriched each other.

\section{Variation Theory - a theory about teaching and learning}

Variation theory describes necessary conditions of learning in relation to a specific learning content, an object of learning (Lo, 2012; Marton, 2015). The object of learning has two sides: the content and the capability. The theory focuses on how discernment has an essential importance to learning. It is based on two main assumptions (Marton, 2015): (a) We perceive a phenomenon in different ways depending on which aspects of it we discern and (b) we can only discern that which varies.

How we perceive an object of learning depends on which aspects we discern. When we learn, we discern new aspects and relate them to our prior knowledge, enabling us to see the phenomena in a new, more complex way (Marton \& Booth, 1997; Marton, 2015). The learning process also includes our disregarding aspects that are not necessary for the phenomenon to be what it is (Marton, 2015). For example, if we understand what a chair is, we have discerned that it has a seat, a backrest and one or more legs. But we are also able to disregard its colour and material and only look at its shape when we classify it as a chair. Aspects that the learner needs to discern in order to see the phenomenon or the object of learning in a more powerful way are called critical aspects. In a teaching context it is essential to find these aspects. The critical aspects are related to the object of learning as well as to the students who are being taught. Since the aspects are not only connected to the content, they need to be searched for and found. When they are made visible for students, it enables them to learn.

Teaching should make the critical aspects discernible for students (Lo, 2012; Marton, 2015). According to Variation Theory we learn new things by seeing differences instead of sameness. Hence, when teachers use variation in a conscious way, it enables the students to learn. Three different patterns of variation can be used: contrast, generalization and fusion. When we want the students to discern aspects that they so far have not seen (the critical aspects), they can be made visible if they vary against an invariant background. By contrasting at least two features in a dimension of variation, they are made discernible (ibid.). For example, if we want the students to discern the aspect that $a$ chair has a backrest, we contrast it with a piece of furniture that has not got one, though in other ways they are similar. Thus, by contrasting a 
wooden, white chair with a wooden, white stool, the backrest is discernible for a student who has not yet discerned it. For the learner to easily see the demonstrated contrast, variation of the focused aspect (the backrest) is not enough; all the other aspects such as colour, material and size, for example, should be invariant. When an aspect has been discerned, it has to be generalized. Now the focused aspect is invariant and other optional aspects vary. In the previous example, optional aspects such as colour and material vary, by showing different chairs in different colours and different materials. In this way, the learner can explore the limits of the aspect and see that a chair may look different, but it always has a backrest. Through contrast and generalization, aspects have been separated from the whole. Finally the aspects are put together again, in a fusion. Then both the focused aspect and the optional aspects vary.

\section{How the Learning Study was carried out}

When I started my doctoral studies, I had the opportunity to lead a research project together with my colleagues, using Learning Study as a method. I suggested that we should focus on students' story-writing. Before I became a teacher researcher I had been a teacher who taught writing (among other things) for nearly 15 years. My experience was that it was difficult to enable students to develop their story-writing further. In general, students wrote stories with poorly developed plots. I pondered a lot about how to teach this skill in a better way. This was an issue that the other teachers also found important and difficult; consequentially we agreed that our object of learning should be to write stories with a well-developed plot. The group of teachers that conducted this study, including me, was composed of teachers that had varying lengths of professional experience, spanning from a recently graduated teacher to a teacher with more than 40 years of teaching experience. I had been a teacher for 15 years. We all taught students that were 9 to 10 years old. I worked part-time as a teacher during the research project, but my primary occupation was doctoral studies. The other teachers worked full time as teachers. I had the role of a research manager who led the team, and the other teachers were co-researchers. During our meetings, all of us could raise questions and reflect upon the learning sessions that were carried out. I always prepared the meetings by choosing parts from the video recording that I wanted us to analyse and discuss. I also continued the analysis after our meetings. Overall, the analysis was partly made by the research team and partly by me alone.

The process started off with a pilot study which was conducted by me alone, but was discussed in the teacher research group. The pilot study was carried out in a class that would not be part of the main study. The purpose was to gain knowledge about what kind of stories ten-yearold students wrote. Stories were written by 27 students and analysed based on how the plot was constructed. Six of the students were interviewed in order to find qualitatively different conceptions about story-writing.

After the pilot study, the main study was conducted. In all, five cycles were carried out. Each cycle consisted of pre- and post-assessment of students' written stories, the planning of lessons, conducting them and finally analysing and revising them. The first four cycles were carried out at our own school by the teacher research team. We had weekly meetings where we discussed the study. After the first four cycles, the teacher research team was dissolved. A few months later, I alone did one more cycle at another school. The purpose was to try out and further explore the previous findings and the object of learning. In the first three cycles 
the class teacher performed the lessons. In these cycles, I and the other teachers primarily were observers. In the last two cycles, I was the teacher performing the lessons.

Throughout the whole process, the object of learning, its critical aspects and how they could be taught were central. We made assumptions about critical aspects based on an analysis of interview data, students' stories written before and after the lessons, video recordings from the lessons and literature about creative writing. These tentative aspects were then tested in the classroom setting. Through that process, new critical aspects were found while others were refined or abandoned. The analysis of the video recordings addressed how the critical aspects were enacted in the classroom, how patterns of variation were used, as well as an examination of the student's conceptions. When the texts written by the students were analysed, each student's pre-assessment was compared with the same student's postassessment.

The results of the study focused on two questions (1) what the students need to discern to develop the capability and (2) how this can be enacted in the classroom. The first question was answered by describing critical aspects and the second question described patterns of variation that were powerful to use in order to make the critical aspects discernible for the students. The findings of this study will not be presented as a whole (they can be read in Thorsten, 2014), nor will the teachers' learning be in the foreground (this issue is addressed in Thorsten, 2015). Instead, the study will be used to show how and why Learning Study can be seen as a clinical research practice.

\section{Learning Study as a clinical research practice}

A Learning Study can be seen as a clinical research practice (Carlgren, 2012). In the process of doing Learning Study, there are elements of both the teaching practice and the academic practice. For me as a teacher researcher, this was apparent during the entire process. In the text below, conducting the Learning Study will be discussed in relation to the four areas that Labaree (2003) points out as dichotomies. In this study, it will be shown how they were intertwined and affected each other. With these concepts in the foreground, the process as well as the results will be illustrated by using examples from the research project. The focus is on how different kinds of knowledge and different perspectives affect and permeate the conducting of a Learning Study, seen from a teacher researcher's point of view.

\section{Normative as well as analytical}

A teaching situation is always more or less normative. The curriculum sets guidelines for the content of the teaching, and the learning of the students is assessed based on these guidelines. The students should develop certain abilities and these abilities are valued in relation to specific goals or criteria. In a Learning Study, teachers choose an object of learning to explore. Since teachers' main task is to educate students and to enable them to develop towards specific goals, many of the questions that teachers are asking themselves are, in this sense, normative. Carlgren (2012) and Stenhouse (1981) argue that research on education should address questions that are relevant for the teaching profession. The object of learning in the study at hand was chosen and specified based on our joint experience of teaching storywriting. The research questions and the object of learning were basically the same, and the 
other co-researchers and I had the same interest. We wanted to explore the object of learning, the critical aspects and how they could be enacted in a powerful way. This means that even though I was the one leading the team, as well as the only one formally employed as a researcher, we were all researchers and we all had the same object of research.

Even if the questions of the study were raised in a normative context, the aim of the lessons and the definition of the object of learning were not static and strictly connected to predefined learning goals. An object of learning is dynamic and is partly defined based on how the students perceive it (see Marton, 2015). This implies that questions that are studied and handled in a normative context can still be addressed analytically. The questions asked were investigated systematically through the design of Learning Study. The analysis focused on exploring the object of learning and how to teach it in order to enhance student learning. Generally, teachers focus on the students they now teach and on how to enable them to learn as much as possible (Bulterman-Bos, 2008). In research, however, the focus is mostly not on these particular students, but on understanding something else through them. In this study, this was not a contradiction since every teaching session focused on making it possible for these students to learn. It was through understanding the learning of these students that we would gain knowledge about the object of learning. In order to understand the students' learning and how the object of learning was constituted, we did not primarily study if the students understood, instead we analysed how they perceived and handled the object of learning.

For example, when the interviews in the pilot study were analysed, different conceptions about story-writing appeared (Thorsten, $2014 \mathrm{pp} 70-71$ ). One of the categories that was found showed that when writing the plot of a story, some students strived to make the events as pleasant as possible for the main characters. Even if the story had a problem, it was solved immediately. In the following excerpt, a student has written a story about a couple of friends who were exploring an island. Suddenly it started to rain, and then the friends went back home and the story ends. When the student was asked about her own story, she said that she really liked the ending of it.

Interviewer: Why do you think the ending [of the story] is good?

Student: When it starts to rain, it's good to go home, isn't it?

The ten year-old girl who wrote this story created the plot based on what chain of events that would be best for the characters: If it rains, it is good to go home. She did not consider whether or not the story would be interesting and exciting for a reader. For her, story-writing was about letting the characters have a good experience, not about giving the reader a good reading experience. If we want the students to write stories that are interesting for a reader to read, it is not successful to primarily focus on the experience of the characters. Based on this analysis, we found and described a critical aspect that the students needed to discern: To see the difference between giving the characters an ideal experience and giving the reader an experience (Thorsten, 2014, p 104). This aspect then needed to be enacted in the teaching.

When studying the students' writing, their interviews (as in the previous example) as well as the lessons, the purpose was normative as well as analytical. We wanted the students to develop a specific ability (to write stories with a well-developed plot) and, therefore, we valued different conceptions and ways of doing, in different ways. The research team had values and opinions about how the writing should be performed in a powerful way. These values were based on the curriculum, our previous experiences and previous research. In this sense we were normative. However, the first part of the analysis was not mainly connected to 
our ideas about writing. In this part, it was focusing foremost on how the students now handle the ability, without giving it different values. At this point, the aim was to understand the logic of the child's reasoning in order to understand what might be critical for them to discern. In the next step, we related and gave value to the conceptions of the students about our interpretation of the object of learning. We found the critical aspects by using normative as well as analytical skills.

Based on my experience as a teacher researcher, I agree with Bulterman-Bos (2008): there does not have to be a contradiction between being normative and analytical. In research it is essential to do a thorough analysis, where the researcher can see what is relevant, but also what is meaningful. The study has to be meaningful for those who are involved in it. The teachers were all dedicated in designing their lessons to help their students develop the capability. To test, analyse and describe what ought to be done in order to enhance the participating students' learning was central throughout the whole process. The study not only analysed a teaching situation, it also strived to improve it.

\section{The experiential as well as the theoretical}

The experiential practice-based knowledge as well as the theoretical knowledge were, in different ways, important to the entire process. The teachers' experience combined with theories about writing, writing instruction and Variation Theory, influenced the process and the results of the study.

Theories about writing and writing instruction were discussed throughout the process. In the beginning they deepened our knowledge about writing in general as well as about different ways of teaching it. The theories were on different levels, some very concrete and some more theoretical. We discussed the theories and related them to our experiences when we analysed and tried out which aspects might be critical for the students to discern. Variation Theory was the theoretical framework that the theories were related to. Variation theory provides theoretical tools and guidelines on how to understand students' learning and how to design teaching that can help students to discern new aspects. But the theory cannot live by itself. It has to be lived in examples and exercises (see Thorsten, 2015). Therefore, the prior teaching experience and the knowledge about the students that were now being taught, were crucial in the planning of the lesson design. Following, I will give an example of how Variation Theory, theories about writing and the teachers' prior experience had different roles in relation to the critical aspect that was described in the previous section.

The critical aspect To see the difference between giving the characters an ideal experience and giving the reader an experience (Thorsten, 2014, pp 104-111) was found when analysing empiric data. But it was confirmed and put into a context when it was compared to previous research. Previous research (Alamargot \& Fayol, 2010; Bruner, 2002; Garton \& Pratt, 1989; Graves, 1994; Lundberg, 1984; McCutchen, 2006) had showed that the awareness of a reader is critical for all kinds of writing. Thus, it is important that students develop this ability. Through the analysis we could see what students focused on when they did not take the reader's perspective. Instead of focusing on the reader, they could be focusing on the character's perspective (as was shown in the example above, p 6). According to Variation Theory we should use the students' current conceptions as a starting point when we teach. By using the described conception and contrasting with the perspective of a reader, a dimension of 
variation could be opened that would make the aspect possible to discern for the learner. To do this, a story with a well-developed plot was contrasted with a poorly developed one. Both of the texts were about two boys hiking in the mountains when it suddenly starts to rain. In the first one, the boys immediately run back to the cabin. In the second, one of the boys falls down and hurts himself before they eventually end up in the cabin. Both of the stories had the exact the same beginning and end, the only thing that differed was whether or not the story had a chain of events between the main problem and the main solution. Thus, the focused aspect varied against an invariant background which, according to Variation Theory, is a condition that makes learning possible (Marton, 2015).

When the texts were written, our practice-based knowledge about what usually interests 910-yearolds was important, as was knowledge about how the texts should be presented in a successful way (reading it aloud, but giving all of the students a copy of their own etc.). The pattern of variation had to be embedded in a powerful context that suited the students. For this part our joint practice-based knowledge was central. When the lesson was conducted, the students got to discuss which of the texts they would like to experience themselves and which one they enjoyed reading. Almost all of the students said that they wanted to experience the first, short text (the one with a poorly developed plot), since nobody got hurt. They also concluded that they wanted to read the second text since it was more exciting. In all of the five cycles, the texts were discussed with the students, but the activity was carried out in different ways. The analysis from the first cycle showed that the students could discern the contrast between the characters' experience and the reader's experience. Even so, for learning to take place, the contrast had to be accompanied by discussions where the differences between the perspectives were analysed and pointed out. In the next cycles the theory was used more explicitly in the teaching. This enabled the students to discern the aspect.

When the analysis of the lessons was conducted, the experiential as well as the theoretical knowledge was important. In order to fully perceive what happens in a classroom, teaching experience is necessary (Bulterman-Bos, 2008). It was through the lens of our joint experience that we perceived the classroom. If we are going to study a classroom and if our purpose is to generate knowledge that can improve the teaching, we need to have the eyes of a connoisseur, not a novice (ibid.). Even if the experience-based knowledge is important, it is not enough (Elliot, 2012). There is always a risk that you only see the expected and that you cannot see beyond your horizon. The methodology of Learning Study in combination with Variation Theory included systematic as well as theoretical tools to analyse and to revise the teaching in order to enhance the students' learning. Variation Theory provided a framework. It made the analysis focus on specific questions. The tacit knowledge in that process was partially articulated and examined, which led to our own conceptions about teaching being changed and developed in many ways (see Thorsten, 2015). This is in accordance with Tan (2014), who describes that teachers personal (often tacit) theories about teaching and learning can be developed when they are combined with an explicit learning theory. The present paper does not, however, focus on teachers' learning in a Learning Study (results about this can be read in Thorsten, 2015), but on the knowledge generating process. Nevertheless, when the knowledge of the whole research team was articulated and developed, it also affected the analysis and enabled it to be deepened. 


\section{Personal as well as intellectual}

A presumption for this study was that the teachers who carried out the lessons had general teaching skills. It enabled them to handle the complex classroom situation and interact with students. According to Bulterman-Bos (2008), when data is analysed it can be an advantage to have personal knowledge about the research object since it gives direction towards what the analysis should address. The analysis was done several times and was partly done by me together with the teachers, as well as partly by myself alone. It was enriched by our joint teaching knowledge.

The lessons in the two last cycles were carried out by myself. To teach and to analyse teaching requires, according to Lampert (1990), different kinds of knowledge. When the one who is teaching in a research study has knowledge that includes both the practice-based, personal knowledge and the theoretical, intellectual knowledge, the analysis can be deepened. Analysing your own teaching can be difficult. However, since the analysis in a Learning Study does not focus on the teaching style, but rather on how the object of learning and the critical aspects are enacted in the classroom as well as on how the students' learning is affected, the analysis can be enriched by the researchers' participation. When I as a researcher conducted some of the teaching, it contributed to the study in two different ways. Firstly, the experience of handling the object of learning with the students gave me new, personal and embodied knowledge that affected the analysis. Secondly, since the object of learning and its critical aspects were supposed to be enacted in the lessons and I was the person who had studied them the most, it was likely that the validity could be raised if I performed the lessons. It ensured that the things that should be tested were tested. It made it more probable that the lesson plan was followed, as well as that the plan could be affected by thoughts and comments from students during class. When the lessons were performed, personal as well as intellectual knowledge affected the enactment of the lesson. One example is from the last phase of a learning session in the fifth cycle.

The students were divided into groups where they had to plan and rehearse a short drama (Thorsten, 2014, pp 96-100). In the previous cycles we had noticed that many groups could not perform their dramas in a way that could be comprehensible for the audience, which led to the following critical aspect: To discern that a story is a product of the imagination and that a reader/the audience should be able to understand the content of the story. Therefore, I had this aspect in mind when I coached the groups. Guiding the groups in this work demanded both personal and intellectual knowledge. The personal knowledge was based on emotions and an ability to understand subtle signs from students. These signs enabled me to see and understand when the students were confused and needed further guidance. The intellectual knowledge was based on the earlier cycles and on keeping in mind what we wanted the students to discern as well as how I could create a contrast that helped the students.

The above reasoning assumes that personal as well as intellectual knowledge influence the study. These two are intertwined and can be a resource in the process. However, for this to be an advantage and not a hindrance, the alternation between closeness and distance to data was necessary. Spontaneous thoughts, feelings and reflections were written down immediately after the learning sessions, both when I was observing (Cycles 1-3) and when I was teaching (Cycles 4-5). A first analysis was done close to the enactment of the lessons. This made it possible that the embodied, personal knowledge was taken into account. At the research meetings we shared spontaneous feelings and reflections as well as those that were more intellectual and connected to theory. 
Even if closeness to data and personal knowledge can be a resource, it can also prevent the teacher researcher from seeing parts that might be essential. Polanyi (1962) describes that tacit knowledge to some extent cannot be verbalized and that it can be so incorporated in the person that it is difficult for him/her to see it. According to Larsson (2005), the researcher needs to be aware of his/her perspective in order to be critical of it. Since I was so involved in the enactment of the study, the risk was that I could have difficulties distancing myself from the data; this also applied to my colleagues. To ensure criticality and that the analysis was thorough, it was conducted several times. Also, several months after the first analyses, a new analysis was done. Data was then studied again strictly using Variation Theory as an analytical tool. By this time, the teacher research team had dissolved and I analysed the transcripts looking for how the students perceived the object of learning and how patterns of variation were used. Also the students' texts written before and after the lessons were analysed more deeply. Since I had gained deeper knowledge about story-writing and what we wanted the students to learn, the analysis of the stories written by the students now focused on four criteria (the number of problems and solutions, comprehensibility, coherence, and the plot). These criteria were based on the meaning of the object of learning on a level adjusted for 910 -year-olds. The part that was focused on the number of problems and solutions made it possible to get an overview of the students' writing and how it had developed.

In this second, more distanced analysis new things appeared that previously had been hidden to me. Analyses at different times were important because they provided different kinds of knowledge being able to be taken into account. The personal knowledge gave insights during the lessons and also directly after the lessons were conducted. For example, these insights were connected to tempo, whether or not our examples were powerful and whether or not specific students could understand and take part in the learning session. The intellectual knowledge was primarily connected to the use of Variation Theory and doing an analysis in a systematic way. Even if the personal and intellectual knowledge are described separately, they were also intertwined. The embodied knowledge and the emotions affected the thinking as well as our focus and interest during the lessons. Likewise, the intellectual focus on handling the critical aspects affected how we experienced the teaching. For the entire process, the use of a learning theory and the systematic methodology of Learning Study were essential, since it provided a framework and a focus for the research questions.

\section{The particular as well as the universal}

When doing a Learning Study the particular is studied in depth, which means that the knowledge that is generated is precise and that it can be part of a greater knowledge building in the teaching profession (Carlgren, 2012).

The main findings in this Learning Study are a description of the meaning of the critical aspects that were found and how they can be enacted in the classroom in order to make learning possible (Thorsten, 2014). They can be connected to two areas described in previous research about writing in a school context. In total, eight critical aspects were found (see below). The first four can be related to research about the main structure of stories and how to teach it (see Christie \& Derewianka, 2008; Elbow, 2000; Graham, 2006; Temizkan, 2011; Waitman \& Plucker, 2009). The next four aspects are related to research concerning that the writer needs to be aware of a reader (Alamargot \& Fayol, 2009; Bruner, 2002; Garton \& Pratt, 1989; Graves, 1994; Lundberg, 1984; McCutchen, 2006). 
(a) Critical aspects related to the main structure in stories:

- To discern that a main problem and its solution can consist of several problems and solutions.

- To discern that events between the main problem and the main solution can vary.

- To experience story-writing as a problem solving process.

- To discern that the problems and solutions should be intertwined into a coherent and credible whole based on the logic of the story.

(b) Critical aspects related to the awareness of a reader:

- To discern that a story is a product of the imagination and that a reader should be able to understand the content of the story.

- To discern that the purpose of stories is to entertain.

- To see the difference between giving the characters an ideal experience and giving the reader an experience.

- To discern that unusual events often make the story more exciting than common and expected events.

Even if the critical aspects relate to previous research, they were not fully described in it. This study contributed by defining and specifying these areas. By deeply studying an object of learning, we gained knowledge about the relation between teaching and learning and about how the object of learning is constituted. This kind of knowledge can only be generated by deeply examining it in a natural school setting. In the following, I will give an example of how we found one of the critical aspects, an aspect that proved to be especially important.

The analysis of the students' stories showed that most of them had a poorly developed plot (Thorsten, 2014, pp 81-84, 111-115). Connecting this analysis with previous research and with the way students talked about it during the interviews in the pilot study made us in the first cycle address the following aspect: To discern that a story has a plot. To draw the students' attention to the importance of a plot, we used the same text contrast that was mentioned before (about the two boys who were hiking) to make this aspect discernible as well. The contrast between the two stories was used in all of the cycles, but it was not fully successful in the first one. In the first cycle the terms 'plot' and 'chain of events' were used without being problematized. The teaching in the first cycle gave the students the opportunity to discern that a story should have a well-developed plot, though what a plot really is was not handled. The analysis of the lessons together with the pre- and post-assessment, led to the critical aspect being revised and defined in a new way. We realized that a plot is based on problems and solutions, and that this was critical for the students to discern. We changed the critical aspect into this: To discern that a main problem and its solution can consist of several problems and solutions. In the next cycle we used the same texts as before, but this time the teacher helped the students to compare the texts by counting the number of problems and solutions in each of them. After the text contrast, a short film was shown for the students. The film was analysed based on the structure of problems and solutions. This made it possible for the students to generalize the aspect. The same structure was also used in other activities in the lessons. It permeated the whole design and had a big impact on students' writing in the post- 
assessment. From the second cycle, most of the students wrote longer stories with a betterdeveloped plot after the lessons than they did before. See the following example from a description of a student's texts before and after the lessons in Cycle two (example from Thorsten, 2014, p.83). The stories are described in terms of problems and solutions.

Pre-assessment:

Problem: Two brothers are heading against a waterfall.

Solution: They crawl up on a branch and then they walk home.

Post-assessment:

Problem: Wolves want to attack two children (named Vanja and Vilgot).

Solution: The children climb up a tree.

Problem: The children are hungry.

Solution: They have brought some food that they eat.

Problem: The children want to climb down the tree but a wolf is guarding it.

Solution: The wolf falls asleep.

Problem: Vanja stumbles when they are climbing down from the tree. The wolf wakes up.

Solution: The children climb up another tree. The wolf falls asleep again.

Problem: Vanja falls down from the tree; she is bleeding from her head.

Solution: Vilgot cools the wound with snow. He carries Vanja home.

Problem: The wound needs to be bandaged.

Solution: Vilgot finds a bandage at home which he uses to stop the bleeding.

This writing example is typical for the way the story-writing developed. The lessons made it possible for students to discern not only that a story should have a well-developed plot, but also what a plot is. The description of a plot consisting of several problems and solutions is a simplification of the story structure. However, it does not misrepresent the foundation of a story and, for students aged 9 to 10, it was proven to be a successful tool.

The critical aspect described above, was explored and found in a specific context. However, this does not make it only applicable to these particular students at this particular school. In a Learning Study the researcher gives a theoretical description of an object of learning and its critical aspects (Marton \& Runesson, 2015). Even if the aspects were found in a specific context and even if they are related to the students who were taught, they are also a part of what constitutes the object of learning and are, in that sense, universal. The critical aspects that were found in this study are probably not the only aspects that can be critical for students to discern in order to write stories with a well-developed plot. Other teachers can use the results and test them in a new setting, and in that way increase the knowledge; hence, the research is cumulative (Carlgren, 2012; Marton \& Runesson, 2015). This has been shown by Runesson and Gustavsson (2012) and Kullberg (2007) in studies where teachers could use results from prior Learning Studies.

\section{Concluding remarks}

If we want educational research to have an impact on teachers' daily work in the classroom, we need to address and explore questions that are relevant for teachers. Basic questions for teachers are what the students need to learn and how the content can be taught in a powerful way. Furthermore, the teachers' knowledge needs to be seen as a resource and not a 
hindrance in the research process. One example where both of these aspects are considered is Learning Study. The research questions are raised by practitioners and the perspective of the practitioner continues to influence the entire process. Even if this perspective is important, it is not enough. In a Learning Study, the perspective of a researcher is combined with a methodology and with a theory which makes it possible to see and analyse even more aspects of teaching and learning. The combination of practice knowledge and theory enables the asking of questions from different points of view and the use of different kinds of knowledge in the process.

The results that are generated should be meaningful and relevant for teachers. Hiebert et al. (2002) argue that teachers would gain from sharing a professional knowledge base. They suggest that the lesson could be a sharable part and build the basis for theories about teaching and learning. The result in a Learning Study, using Variation Theory, is not presented as a lesson plan. It does not include thick contextual descriptions of the school context. Instead, it is a theoretical description of what students need to have the opportunity to discern in order to develop a specific ability. This description has emerged from practice and from an analysis conducted by practitioners. Since the process is influenced by the fact that the research team consists of teachers, so too are the results, which has been discussed in this paper.

Using Learning Study and Variation Theory provided a framework where different kinds of data as well as different kinds of knowledge could be the base of the analysis. By using joint teacher experience, previous research about story-writing and a learning theory in a cyclic approach, assumptions were tested and evaluated which led to critical aspects being specified and defined. The method is an interventionist research practice where elements from the academic practice and the teaching practice are important. This does not mean that it is only an alternation between the two practices; instead they are in many ways intertwined. Being a teacher researcher, it has been apparent that various views and various kinds of knowledge are not used separately; they are combined. This implies that when the academic practice and the teaching practice interact, they are not only two parts; instead they merge into something else which can be described as a clinical research practice.

\section{References}

Alamargot, D. \& Fayol, M. (2009). Modelling the Development of Written Composition. In R. Beard, D. Myhill, M. Nystrand \& J. Riley (Red.), The SAGE Handbook of Writing Development. SAGE Publications Ltd. (e-book).

Bruner, J. (2002). Making Stories: Law, Literature, Life. New York: Farrar, Straus and Giroux.

Bulterman-Bos, J. (2008). Will a Clinical Approach Make Education Research More Relevant for Practice? Educational Researcher, 37(7), 412-420.

Carlgren, I. (2012). The learning study as an approach for "clinical" subject matter didactic research. International Journal for Lesson and Learning Studies, 1 (2), 126-139.

Christie, F. \& Derewianka, B. (2008). School Discourse. New York: Continuum.

Cochran-Smith, M. \& Lytle, S. (1999). The Teacher Research Movement: A Decade later. Educational Researcher, 28 (5), 15-25.

Elbow, P. (2000). Everyone Can Write. New York: Oxford University Press. 
Elliot, J. (1991). Action research for educational change. Milton Keynes, Philadelphia: Open University Press.

Elliot, J. (2012). Developing a science of teaching through lesson study. International Journal of Lesson and Learning Studies, 1 (2), 108-125.

Garton, A. \& Pratt, C. (1989). Learning to Be Literate: The Development of Spoken and Written Language. Oxford: Basil Blackwell Ltd.

Graham. S. (2006). Strategy Instruction and the Teaching of Writing. In C. MacArthur \& S. Graham (Red.), Handbook of Writing Research (s. 187-207). New York: The Guilford Press.

Graves, H. D. (1994). Skriv- och läsbefruktning. Göteborg: Daidalos AB.

Hiebert, J., Gallimore, R. \& Steigler, J. W. (2002). A Knowledge Base for the Teaching Profession: What Would It Look Like and How Can We Get One? Educational Researcher, 31(5), 3-15.

Labaree, D. F. (2003). The peculiar problems of preparing educational researchers. Educational Researcher, 32 (4), 13-22.

Lampert, M. (1990). When the Problem Is Not the Question and the Solution Is Not the Answer: Mathematical Knowing and Teaching. American Educational Research, 27 (1), 29-63.

Larsson, S. (2005). Om kvalitet i kvalitativa studier [Quality in qualitative studies]. Nordisk Pedagogik, 1 (25), 16-35.

Lewis, C. (2009). What is the nature of knowledge development in lesson study? Educational Action Research 7 (1), 95-110.

Lo, M. L. (2012). Variation Theory and the Improvement of Teaching and Learning. Göteborg: Göteborgs universitet.

Lundberg, I. (1984). Språk och läsning [Language and reading]. Umeå: Unitryck.

Marton, F. \& Booth, S. (1997). Learning and Awareness. Mahwah, NJ: Erlbaum.

Marton, F. (2015). Necessary conditions of learning. New York, NY: Routledge.

Marton, F. \& Runesson, U. (2015). The Idea and Practice of the Learning Study. In K. Wood \& S. V. Sithamparam (Eds.), Realising Learning. Teachers' professional development through lesson and learning study. New York and London: Routledge.

McCutchen, D. (2006). Cognitive Factors in the Development of Children's Writing. In C. MacArthur \& S. Graham (Red.), Handbook of Writing Research (s. 115-130). New York, N Y: The Guilford Press.

Newton, P., \& Burgess, D. (2008). Exploring Types of Educational Action Research: Implications for Research Validity. International Journal of Qualitative Methods, 7 (4), 18-30.

Pérez, Á., Soto, E. \& Serván, J. (2010). Participatory action research and the reconstruction of teachers' practical thinking: lesson studies and core refelection. An experience in Spain. Educational Action Research, 18 (1), 73-87.

Polanyi, M. (1962), Tacit knowledge, Terry lectures, Yale.

Somekh, B. \& Zeichner, K. (2009). Action research for educational reform: remodelling action research theories and practices in local contexts. Educational Action Research, 17 (1).

Stenhouse, L. (1981). What counts as research? British Journal of Educational Studies, 2, 103-114. 15

Temizkan, M. (2011). The Effect of Creative Writing Activities on the Story Writing Skill. Educational Sciences: Theory \& Practice, 11(1), 933-939.

Tan, M. S. Y. (2014). Enriching a collaborative teacher inquiry discourse: exploring teachers' experiences of a theory-framed discourse in a Singapore case of lesson study. Educational Action Research, 22 (3), 411-427. 
Thorsten, A. (2014). Perspektiv och problemlösning $i$ berättelseskrivande. Vad elever behöver lära sig och hur det kan synliggöras $i$ undervisningen [Perspectives and problem solving in story writing. What pupils need to learn and how teaching can make it visible.] (Licentiate thesis). Jönköping University, Sweden.

Thorsten, A. (2015). How teachers' practice knowledge is used and challenged in a Learning Study using Variation Theory as a tool. International Journal of Lesson and Learning Studies. 4 (3), 274-287.

Waitman, G. R. \& Plucker, J. A. (2009). Teaching Writing by Demythologizing Creativity. In S.B. Kaufman (Red.), The Psychology of Creative Writing (s. 287-315). New York: Cambridge University Press. 